\title{
Solid State Physics of Transuranics
}

\author{
L. J. Termenello, P. G. Allen, D. K. Shuh, J. Terry
}

\section{August 22, 2000}

Lawrence

Livermore

National

Laboratory 


\section{DISCLAIMER}

This document was prepared as an account of work sponsored by an agency of the United States Government. Neither the United States Government nor the University of California nor any of their employees, makes any warranty, express or implied, or assumes any legal liability or responsibility for the accuracy, completeness, or usefulness of any information, apparatus, product, or process disclosed, or represents that its use would not infringe privately owned rights. Reference herein to any specific commercial product, process, or service by trade name, trademark, manufacturer, or otherwise, does not necessarily constitute or imply its endorsement, recommendation, or favoring by the United States Government or the University of California. The views and opinions of authors expressed herein do not necessarily state or reflect those of the United States Government or the University of California, and shall not be used for advertising or product endorsement purposes.

This work was performed under the auspices of the U.S. Department of Energy by the University of California, Lawrence Livermore National Laboratory under Contract No. W-7405-Eng-48.

This report has been reproduced directly from the best available copy.

Available electronically at http://www.doc.gov/bridge

Available for a processing fee to U.S. Department of Energy

And its contractors in paper from

U.S. Department of Energy

Office of Scientific and Technical Information

P.O. Box 62

Oak Ridge, TN 37831-0062

Telephone: (865) 576-8401

Facsimile: (865) 576-5728

E-mail: reports@adonis.osti.gov

Available for the sale to the public from

U.S. Department of Commerce

National Technical Information Service

5285 Port Royal Road

Springfield, VA 22161

Telephone: (800) 553-6847

Facsimile: (703) 605-6900

E-mail: orders@ntis.fedworld.gov

Online ordering: http://www.ntis.gov/ordering.htm

OR

Lawrence Livermore National Laboratory Technical Information Department's Digital Library

http://www.llnl.gov/tid/Library.html 


\section{Final LDRD Report for 98-ERD-040}

Solid State Physics of Transuranics

\section{Louis J. Terminello, P. G. Allen, D. K. Shuh, J. Terry}

\section{Abstract:}

The experimental validation of first principals calculations of plutonium and its alloys is an important part of LLNL's science-based stockpile stewardship mission. This project has addressed this issue in the following ways. We have measured the electronic structure of U, $\mathrm{Pu}$, and their alloys using valence band photoemission (PES), Soft X-Ray Fluorescence (SXF), and X-Ray Absorption Spectroscopy (XAS). In the long term, this will allow a direct comparison between calculated and measured density of electronic states, identifying the degree of f-electron localization in the alloys, and thus, permit selection of the best modeling code.

\section{Introduction:}

In recent years, the focus of the Laboratory has turned towards a science based approach to evaluate and predict the life-span and long-term safety of the nuclear stockpile. To this end, a great many modeling and measuring efforts are underway to address these concerns. This project from the Glenn T. Seaborg Institute for Transactinium Science (ITS) in the Isotope Sciences Division (ISD) of C\&MS addresses a fundamental component of this science based stewardship endeavor: The experimental validation ${ }^{1}$ of first principals calculations ${ }^{2,3,4}$ of uranium, plutonium and their alloys that are the basis of many stockpile systems models.

We will perform these tasks in the following ways. We will generate validation data for first principals calculations of $\mathrm{U}, \mathrm{Pu}$ and their alloys by measuring the electronic structure (Density of States - DOS) of the material using PES, SXF, and XAS. This will allow a direct comparison between calculated and measured density of electronic states and thus permit selection of the best modeling code needed for further materials property determination. This project also develops the stringent materials handling procedures for the synchrotron radiation techniques at the core of the project - techniques that will prove to be valuable to broader stockpile related missions.

\section{Approach:}

$\mathrm{Ab}$ initio, or first principal calculations of actinides and their alloys are performed to predict their equations of state. The results of the first principals calculations produce a density of electronic states for the material which can then be used to predict the macroscopic properties and behavior of the material under many conditions. While many projects are underway to validate experimentally ${ }^{5}$ the structure of the actinides (high pressure $x$-ray diffraction, for example), no direct validation of the first steps in the calculation cycle are performed at LLNL. The most direct way to validate the results of the initial calculations is to measure the electronic structure of the materials ${ }^{6}$ as a function of phase or alloy composition. We can do this with valence band photoemission and SXF to determine the occupied electronic states and XAS for the unoccupied or empty states.

Current approaches to modeling the electronic structure of $\mathrm{Pu}$, its alloys, and other transuranics rely on the local density approximation (LDA) ${ }^{2,3}$. This approach has been useful 
in modeling many other metals and alloys, but suffers from the limitation that it does not include enough of the electron correlation needed to accurately describe heavy elements (i.e., the strong relativistic effects). Various attempts to overcome this limitation with an adjustable "correlation" parameter in the LDA have led to fairly accurate interatomic distances for $\alpha-\mathrm{Pu}$ and $\delta-\mathrm{Pu}$, albeit with a somewhat unphysical adjustable parameter. It is still unclear if these approaches will be suitable for phase stabilized alloys of $\mathrm{Pu}$, and their improvement is the focus of current ASCI projects. Our goal in this portion of this project has been to measure the electronic structure of $\mathrm{U}, \mathrm{Pu}$, and their alloys to compare to current state of the art calculations and pending calculations on alloys.

One interesting phenomenon that we will be looking for is the localization of the $5 \mathrm{f}$ electrons in the alloys of $\mathrm{Pu}$ which should have intermediate electronic properties between itinerant (delocalized) $5 \mathrm{f}$ electrons in $\mathrm{Pu}$ and the lower actinides, and localized 5f (Kondo effect) electrons in Americium. ${ }^{7}$ Earlier photoemission work ${ }^{8}$ on $\mathrm{U}, \mathrm{Pu}$, and $\mathrm{Am}$ observed the localization in Am, but saw itinerant behavior in the $\alpha$-Pu. The degree of localization for the $5 \mathrm{f}$ electrons in $\mathrm{Pu}$ alloys has direct bearing on the macroscopic properties of these materials (such as heat capacity) and thus underlies the importance of this project to measure the electronic structure of these materials as a means of model validation. Our measurements will be able to provide serendipitous Coulomb-interaction information that will be useful for theorists to refine the correlation correction to their models.

The challenge for this experimental program has been the difficulty of preparing and measuring clean $\mathrm{Pu}$ and $\mathrm{Pu}$ alloy surfaces that are complicated by severe safety concerns. These surfaces, especially those of $\mathrm{Pu}$, are extremely reactive creating a surface layer that can obfuscate the desired bulk electronic structure measurement. Understanding the relationship of the electronic structure modification with alloy formation on this surface reactivity drives our experiments on $\mathrm{U}$ and its alloys. Other groups that characterize $\mathrm{Pu}$ and other actinides using a tunable photon (5-250 eV) plasma source photoemission apparatus produced noisy data that obscure the localization information sought.

Instead, we have overcome the significant technical obstacle of surface preparation by relying heavily on the SXF and XAS techniques. These methods probe the occupied and unoccupied electronic DOS of a material with elemental specificity - something that PES cannot do. These photon-in, photon-out techniques allow us to prepare encapsulated or coated samples in an inert/vacuum environment to protect and passivate the highly reactive $\mathrm{U}$ or $\mathrm{Pu}$, and transport the materials to the synchrotron radiation facility. This procedure also greatly reduces the safety concerns surrounding this experiment - thereby reducing costs as well. The

synchrotron radiation experiments will be performed at the Advanced Light Source - LBNL, and the Stanford Synchrotron Radiation Laboratory.

\section{Milestones Accomplished:}

We have begun the synchrotron radiation SXF and XAS experiments in the first half of FY'98 and have made significant progress in developing the radioactive materials preparation, handling, and analysis procedures needed for the success of this project. We have measured the SXF of $\mathrm{U}, \mathrm{UO}_{2}$, and $\mathrm{UO}_{3}$ samples at the ALS, and $\mathrm{U}$ and $\mathrm{U}-\mathrm{Nb}$ alloys at SSRL. Initial 
interpretation of these results indicate that our samples preparation methods are producing unreacted surfaces that remain pristine throughout the experiment. These results also indicate that we can see evidence for charge transfer in the alloy.

We have successfully performed XAS experiments on the alpha and delta phase of plutonium in FY99. Initial interpretation of these results, indicate that our samples preparation methods are producing unreacted surfaces that remain pristine throughout the experiment. These results also indicate that we can see evidence for charge transfer in the alloy that will be critical for accurate interpretation of the coulomb effects in $\mathrm{Pu}$ and its alloys. Pictured in figure 1 is a comparison of the core level photoabsoption near edge structure from alpha (lower curve) and delta (upper curve) plutonium. The difference in near edge structure is a direct sampling of the difference in empty electronic states in the two phases of plutonium and can be interpreted as evidence of charge transfer in select phases of plutonium. These results are consistent with our earlier work on $\mathrm{U}$ and $\mathrm{Nb}-\mathrm{U}$ alloys where a similar charge transfer was observed.

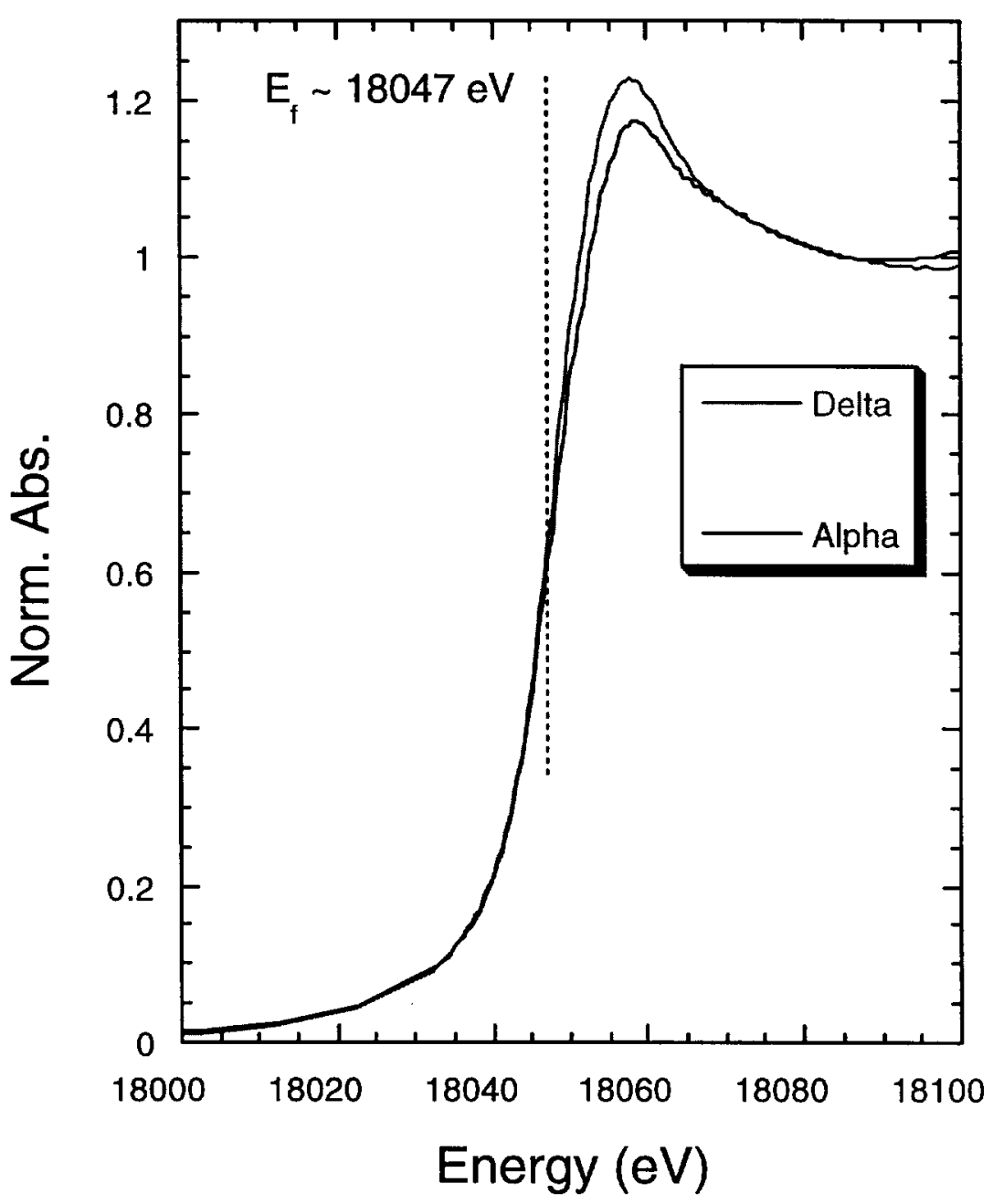

Figure 1: the core level photoabsoption near edge structure from alpha (lower curve) and delta (upper curve) plutonium measured at the Stanford Synchrotron Radiation Laboratory. 


\section{Benefit:}

The primary, and long term, benefit of this project to Lawrence Livermore National Laboratory is in validating the initial steps of the modeling cycle for weapons systems - a modeling cycle that will be asked to predict performance and safety of extended life-span materials, and in determining the actual mechanical property and structural changes that may occur in extended life materials. The immediate benefit of this project has been in the creation of an Enhanced Surveillance Program project on this topic that is directly funded by DNT.

\section{Acknowledgements:}

This work was supported by the Division of Materials Sciences, Office of Basic Energy Science, U. S. Department of Energy, and performed under the auspices of the US Department of Energy by Lawrence Livermore National Laboratory under contract No. W7405-ENG-48. This work was done at SSRL which is supported by the Department of Energy

\section{References:}

General Reference: F. Weigel, J. Katz, and G. T. Seaborg, in J. Katz, G. T. Seaborg, and L. R. Morss (eds), Plutonium, $5^{\text {th }}$ edn., p. 499, 1986.

1. T. Gouder, J. R. Naegele, C. A. Colmenares, J. R. Naegele, and J. Verbist, Inorg. Chim. Acta 140, 35 (1987).

2. A. K. McMahan, J. of the Less-Common Metals 149, 1 (1989).

3. J. Van Ek, P. A. Sterne, and A. Gonis, Phase stability of plutonium. Phys. Rev. B 48, 16280 (1993).

4. P. H. Adler, G. B. Olson, M. F. Stevens, G. F. Gallegos, On the constitutive relations for delta-alpha and alpha-delta martensitic transformation plasticity in plutonium alloys, Acta Metallurgica et Materialia 40, 1073 (1992).

5. L. E. Cox, R. Martinez, J. H. Nickel, S. D. Conradson, et al. Short-range atomic structure of 1 wt-percent $\mathrm{Ga}$ delta-stabilized plutonium x-ray-absorption fine-structure spectroscopy, Phys Rev. B 51, 751 (1995).

6. J. R. Naegele, J. Ghijsen, and L. Manes, Actinides - Chemistry and Physical Properties in : Structure and Bonding, Ed. L. Manes, Vols. 59/60 (Springer, Berlin, 1985) p. 197

7. J. R. Naegele, J. of Nuclear Materials 166, 59 (1989).

8. S.Meot-Reymond and J. M. Fournier, J. of Alloys and Compounds 232, 119 (1996). 